\title{
A Novel Distance between Vague Sets and Its Applications in Decision Making
}

\author{
Weibin Deng, ${ }^{1,2,3}$ Changlin $\mathrm{Xu},{ }^{2,3}$ Jin Liu, ${ }^{1}$ and Feng $\mathrm{Hu}^{2}$ \\ ${ }^{1}$ Key Laboratory of Electronic Commerce and Modern Logistics, Chongqing University of Posts and Telecommunications, \\ Chongqing 400065, China \\ ${ }^{2}$ Chongqing Key Laboratory of Computational Intelligence, Chongqing University of Posts and Telecommunications, \\ Chongqing 400065, China \\ ${ }^{3}$ School of Information Science and Technology, Southwest Jiaotong University, Chengdu 610031, China \\ Correspondence should be addressed to Weibin Deng; d_w_b@163.com
}

Received 6 March 2014; Accepted 23 May 2014; Published 15 June 2014

Academic Editor: Chunyu Yang

Copyright (c) 2014 Weibin Deng et al. This is an open access article distributed under the Creative Commons Attribution License, which permits unrestricted use, distribution, and reproduction in any medium, provided the original work is properly cited.

A novel distance between vague sets (VSs) is presented after the inadequacies of existing distance measures between vague sets are analyzed by artificial vague sets. The proposed method investigates the assignment of degree of hesitation to the membership and nonmembership degree, and the properties are also discussed. The performances of the new method are illustrated by pattern classification problem. Finally, the proposed method is applied into multicriteria fuzzy decision making, where the linear programming method is taken to generate optimal weights for every criterion and the best alternative is obtained by the weighted sum of distance measures between each alternative and the idea alternative with respect to a set of criteria. The experimental results show the effectiveness of the proposed method.

\section{Introduction}

A fuzzy set (FS) $A$, as proposed by Zadeh [1], is a class of objects $U=\left\{x_{1}, x_{2}, \ldots, x_{n}\right\}$ along with a degree of membership function, and the fuzzy sets theory has been applied widely in various fields [2]. The membership function $\mu_{A}(x), x \in U$, assigns to each object a degree of membership ranging between 0 and 1; that is, $\mu_{A}: U \rightarrow[0,1]$. Obviously, $\forall x_{i} \in U, \mu_{A}\left(x_{i}\right)$ is a single value between 0 and 1 . This single value combines the evidence for $x \in U$ and the evidence against $x \in U$, without indicating how much there is of each. The single number tells us nothing about its accuracy. Therefore, as a generalization of fuzzy sets, Atanassov [3] introduced the concept of the intuitionistic fuzzy sets (IFSs) in 1983 and Gau and Buehrer [4] introduced the notion of vague sets (VSs) in 1993. Bustince and Burillo [5] showed that IFSs and VSs are equivalent. The VSs (or IFSs) consider the degree of membership, nonmembership, and hesitation of $x$ to $A$, which make the VSs express the true state of uncertain information better than the fuzzy sets (FSs) [6]. The VSs have been successfully applied into edge detection [7], image segmentation $[8,9]$, fuzzy decision making [10-13], fault-tree analysis [14], pattern recognition $[15,16]$, and so on.

As important contents in fuzzy mathematics, similarity measure and distance measure between VSs, which are involved in fuzzy decision making, pattern recognition, fuzzy reasoning, machine learning, and so forth, have attracted many researchers. At present, there are many distances between VSs, which can be divided into four categories. (1) Distances between VSs based on Hamming distance and Euclidean distance, for example, Atanassov [17] defined the Hamming distances and Euclidean distances between VSs in 1999. In 2000, Szmidt and Kacprzyk [18] considered the degree of hesitation into Atanassov's VSs distances and redefined the Hamming distances and Euclidean distances of VSs, Liu [19] defined the distances formula of VSs in 2005, and so forth. (2) Distances between VSs based on Hausdorff distance, for example, Hung and Yang [20], Grzegorzewski [21], Chen [22], and Yang and Chiclana [23] proposed the Hausdorff distances of VSs, respectively. (3) Distances between VSs based on fuzzy implications, for example, 
Hatzimichailidis et al. [24] presented the distances in 2012. (4) The other distances satisfying the axiomatic definition of distance, for example, Wang and Xin [25] constructed some distances and weighted distances of VSs in 2005, and so forth. In the above-mentioned methods, some only consider the impacts of the degree of membership and nonmembership on the distances of VSs and some consider the impacts of the degree of membership, nonmembership, and hesitation.

The distances between VSs not only meet the axiomatic definition of distance, but also satisfy the definition of distances between VSs presented by Wang and Xin [25] (see Section 2), since there exists a certain relationship between the degree of membership, nonmembership, and hesitation for vague sets. Therefore, in the paper, the defects of the existing distances between VSs are analyzed and discussed in detail firstly, and a numerical example is used to demonstrate these defects. Thereafter, a new distance measure between VSs is proposed, and some properties of the new method are also discussed and proved. In addition, the effectiveness of the proposed method is illustrated by a pattern classification problem. Finally, we apply the new method into the multicriteria fuzzy decision and select the optimal weight of each criterion through the optimization method so as to obtain the best solution based on the weighted distance between candidate solution and ideal solution in each criterion. The final decision-making result shows the effectiveness and the feasibility of the proposed method.

The remainder of this paper is organized as follows. The basic concepts on vague sets are shown in Section 2. The analysis process of the existing distances between vague sets is presented in Section 3. Section 4 proposes a new distance between vague sets, and the performances of the method are evaluated by pattern classification and multicriteria fuzzy decision making in Section 5. The paper is concluded in Section 6 .

\section{Vague Set and Its Operations}

Definition 1 (see [4]). A vague set $A$ in $U$ is characterized by a truth-membership function $t_{A}(x)$ and a false-membership function $f_{A}(x)$; that is,

$$
t_{A}: U \longrightarrow[0,1], \quad f_{A}: U \longrightarrow[0,1],
$$

with condition $0 \leq t_{A}(x)+f_{A}(x) \leq 1, \forall x \in U$, where $t_{A}(x)$ is a lower bound on the degree of membership of $x$ derived from the evidence for $x$ and $f_{A}(x)$ is a lower bound on the negation of $x$ derived from the evidence against $x . t_{A}(x)$ and $f_{A}(x)$ both associate a real number in the interval $[0,1]$ with each point in $U$.

This approach bounds the degree of membership of $x$ to a subinterval $\left[t_{A}(x), 1-f_{A}(x)\right]$ of $[0,1]$. In other words, the exact degree of membership $\mu_{A}(x)$ of $x$ may be unknown but is bounded by $t_{A}(x) \leq \mu_{A}(x) \leq 1-f_{A}(x)$, where $0 \leq t_{A}(x)+$ $f_{A}(x) \leq 1$.

For each vague set $A$ in $U$, the uncertainty of our knowledge about $x$ for $A$ is characterized by $\pi_{A}(x)=1-$ $t_{A}(x)-f_{A}(x)$. If $\pi_{A}(x)$ is small, our knowledge about $x$ is relatively precise; if $\pi_{A}(x)$ is large, we know correspondingly little. If $\pi_{A}(x)=0$, our knowledge about $x$ is exact, and the vague sets degenerate into the fuzzy sets. If $f_{A}(x)$ and $t_{A}(x)=1$ or $f_{A}(x)=1$ and $t_{A}(x)=0$, then the vague sets will revert back to the ordinary sets. For convenience, we denote all the vague sets in $U$ as $\operatorname{VSs}(U)$.

For example, let $A \in \operatorname{VSs}(U)$; if $t_{A}(x)=0.5$ and $f_{A}(x)=$ 0.2 , then vague set $A$ can be interpreted as "the vote for a resolution is 5 in favor, 2 against, and 3 abstentions $\left(\pi_{A}(x)=\right.$ $0.3)$."

Let $A \in \mathrm{VSs}(U)$; if the universe of discourse $U$ is discrete, then

$$
A=\sum_{i=1}^{n} \frac{\left[t_{A}\left(x_{i}\right), 1-f_{A}\left(x_{i}\right)\right]}{x_{i}}, \quad x_{i} \in U .
$$

If the universe of discourse $U$ is continuous, then

$$
A=\int_{U} \frac{\left[t_{A}(x), 1-f_{A}(x)\right]}{x} d x, \quad x \in U
$$

Let $x=\left[t_{x}, 1-f_{x}\right]$ and $y=\left[t_{y}, 1-f_{y}\right]$ be two vague values, where $t_{x}, f_{x}, t_{y}, f_{y} \in[0,1]$ and $t_{x}+f_{x} \leq 1, t_{y}+f_{y} \leq 1$; then the operations of two vague values are as follows:

$$
\begin{gathered}
x \wedge y=\left[\min \left(t_{x}, t_{y}\right), \min \left(1-f_{x}, 1-f_{y}\right)\right] ; \\
x \vee y=\left[\max \left(t_{x}, t_{y}\right), \max \left(1-f_{x}, 1-f_{y}\right)\right] ; \\
x=y \Longleftrightarrow t_{x}=t_{y}, \quad f_{x}=f_{y} ; \\
x \leq y \Longleftrightarrow t_{x} \leq t_{y}, \quad f_{x} \geq f_{y} ; \\
\bar{x}=\left[f_{x}, 1-t_{x}\right] .
\end{gathered}
$$

Let $A, B \in \mathrm{VSs}(U)$, where $A=\sum_{i=1}^{n}\left[t_{A}\left(x_{i}\right), 1-f_{A}\left(x_{i}\right)\right] / x_{i}$ and $B=\sum_{i=1}^{n}\left[t_{B}\left(x_{i}\right), 1-f_{B}\left(x_{i}\right)\right] / x_{i}$; the operations and relations of $A$ and $B$ are as follows:

$$
\begin{gathered}
A \subseteq B \Longleftrightarrow \forall x_{i} \in U, \\
t_{A}\left(x_{i}\right) \leq t_{B}\left(x_{i}\right), \quad f_{A}\left(x_{i}\right) \geq f_{B}\left(x_{i}\right) ; \\
A=B \Longleftrightarrow \forall x_{i} \in U, \\
t_{A}\left(x_{i}\right)=t_{B}\left(x_{i}\right), \quad f_{A}\left(x_{i}\right)=f_{B}\left(x_{i}\right) ; \\
A \cap B=\sum \frac{\left[t_{A}\left(x_{i}\right), 1-f_{A}\left(x_{i}\right)\right] \wedge\left[t_{B}\left(x_{i}\right), 1-f_{B}\left(x_{i}\right)\right]}{x_{i}} ; \\
A \cup B=\sum \frac{\left[t_{A}\left(x_{i}\right), 1-f_{A}\left(x_{i}\right)\right] \vee\left[t_{B}\left(x_{i}\right), 1-f_{B}\left(x_{i}\right)\right]}{x_{i}} ; \\
\bar{A}=\sum_{i=1}^{n} \frac{\left[f_{A}\left(x_{i}\right), 1-t_{A}\left(x_{i}\right)\right]}{x_{i}} .
\end{gathered}
$$




\section{Distances between Vague Sets}

3.1. Definition of Distances between Vague Sets. Distance measure is a function that characterizes the difference between VSs and can be considered as a dual concept of similarity measure. For VSs, the axiomatic definitions of a distance are as follows.

Definition 2. A distance $d$ in a nonempty set $U$ is a real value function $d: U \times U \rightarrow[0,+\infty)$, which satisfies the following conditions, $\forall x, y, z \in U$ :

(1) $d(x, y)=0$ if and only if $x=y$;

(2) $d(x, y)=d(y, x)$;

(3) $d(x, y)+d(y, z) \geq d(x, z)$.

The distance measure must satisfy the three conditions presented in Definition 2. But in vague sets, $t_{A}(x)$ expresses a support degree of $x$ to $A$ and $f_{A}(x)$ expresses a degree of opposition of $x$ to $A$, while $\pi_{A}(x)$ expresses a degree of neutrality of $x$ to $A$, which is a degree of decision that cannot be made currently. So the distances between VSs should also meet the definition presented by Wang and Xin [25].

Definition 3 (see [25]). Let $d$ be a mapping: $\operatorname{VSs}(U) \times$ $\operatorname{VSs}(U) \rightarrow[0,1] . \forall A, B, C \in \operatorname{VSs}(U)$, if $d$ satisfies the following properties:

(1) $0 \leq d(A, B) \leq 1$

(2) $d(A, B)=0$ if and only if $A=B$;

(3) $d(A, B)=d(B, A)$;

(4) If $A \subseteq B \subseteq C$, then $d(A, C) \geq d(A, B)$ and $d(A, C) \geq$ $d(B, C)$.

Then $d(A, B)$ is a distance measure between vague sets $A$ and $B$.

From Definition 3, the inclusion relations between VSs can reflect the distance relations between VSs, so the fourth condition must be satisfied. The existing distances between VSs will be analyzed according to Definitions 2 and 3 in Section 3.2 .

3.2. Analysis of the Existing Distances between Vague Sets. In order to simplify the description, the following notations are used, $\forall A, B \in \operatorname{VSs}(U)$ :

$$
\begin{gathered}
\Delta_{t}(i)=t_{A}\left(x_{i}\right)-t_{B}\left(x_{i}\right), \\
\Delta_{f}(i)=f_{A}\left(x_{i}\right)-f_{B}\left(x_{i}\right), \\
\Delta_{\pi}(i)=\pi_{A}\left(x_{i}\right)-\pi_{B}\left(x_{i}\right) .
\end{gathered}
$$

3.2.1. Distances between Fuzzy Sets. Distances between vague sets are expanded by Kacprzyk according to the distances between fuzzy sets [26]. Therefore, the distances between fuzzy sets are firstly introduced as follows for two fuzzy sets $A, B$ in $U$.
(1) Hamming distance $d_{H}$ and normalized Hamming distance $d_{n H}$

$$
d_{H}(A, B)=\sum_{i=1}^{n}\left|\Delta_{\mu}(i)\right|, \quad d_{n H}(A, B)=\frac{1}{n} \sum_{i=1}^{n}\left|\Delta_{\mu}(i)\right| .
$$

(2) Euclidean distance $d_{E}$ and normalized Euclidean distance $d_{n E}$

$$
\begin{aligned}
& d_{E}(A, B)=\sqrt{\sum_{i=1}^{n}\left(\Delta_{\mu}(i)\right)^{2},} \\
& d_{n E}(A, B)=\sqrt{\frac{1}{n} \sum_{i=1}^{n}\left(\Delta_{\mu}(i)\right)^{2}},
\end{aligned}
$$

where $\Delta_{\mu}(i)=\mu_{A}\left(x_{i}\right)-\mu_{B}\left(x_{i}\right)$.

Formulas (7) and (8) just consider the membership function $\mu_{A}\left(x_{i}\right)$. However, there exists the linear relationship between the membership function $\mu_{A}\left(x_{i}\right)$ and the nonmembership function $f_{A}\left(x_{i}\right)$ for a fuzzy set $A$; that is, $f_{A}\left(x_{i}\right)=1-\mu_{A}\left(x_{i}\right)$, where $\mu_{A}\left(x_{i}\right)=t_{A}\left(x_{i}\right)$. Therefore, if the nonmembership function $f_{A}\left(x_{i}\right)$ is also introduced into the distances between fuzzy sets, then formulas (7) and (8) can be represented as follows, respectively.

(3) Hamming distance $d_{H}^{\prime}$ and normalized Hamming distance $d_{n H}^{\prime}$

$$
\begin{aligned}
& d_{H}^{\prime}(A, B)=\sum_{i=1}^{n}\left[\left|\Delta_{t}(i)\right|+\left|\Delta_{f}(i)\right|\right]=2 d_{H}(A, B), \\
& d_{n H}^{\prime}(A, B)=\frac{1}{n} \sum_{i=1}^{n}\left[\left|\Delta_{t}(i)\right|+\left|\Delta_{f}(i)\right|\right]=2 d_{n H}(A, B) .
\end{aligned}
$$

(4) Euclidean distance $d_{E}^{\prime}$ and normalized Euclidean distance $d_{n E}^{\prime}$

$$
\begin{aligned}
& d_{E}^{\prime}(A, B)=\sqrt{\sum_{i=1}^{n}\left[\left(\Delta_{t}(i)\right)^{2}+\left(\Delta_{f}(i)\right)^{2}\right]}=\sqrt{2} d_{E}(A, B), \\
& d_{n E}^{\prime}(A, B)=\sqrt{\frac{1}{n} \sum_{i=1}^{n}\left[\left(\Delta_{t}(i)\right)^{2}+\left(\Delta_{f}(i)\right)^{2}\right]}=\sqrt{2} d_{n E}(A, B) .
\end{aligned}
$$

Based on expressions (9) and (10), the distances between fuzzy sets are enlarged if fuzzy sets are expressed as the form of vague sets, but there is no substantial influence on the results. Therefore, Atanassov obtained the Hamming distances and Euclidean distances through extending formulas (7) and (8) into vague sets.

\subsubsection{Distance between Vague Sets Based on Hamming Distance and Euclidean Distance}

(1) Atanassov's Distances between Vague Sets. Based on the Hamming distances and Euclidean distances between FSs, 
the distances between vague sets derived by Atanassov are as follows:

$$
\begin{aligned}
& d_{H}^{\text {Ata }}(A, B)=\frac{1}{2} \sum_{i=1}^{n}\left[\left|\Delta_{t}(i)\right|+\left|\Delta_{f}(i)\right|\right], \\
& d_{n H}^{\text {Ata }}(A, B)=\frac{1}{2 n} \sum_{i=1}^{n}\left[\left|\Delta_{t}(i)\right|+\left|\Delta_{f}(i)\right|\right] \\
& d_{E}^{\text {Ata }}(A, B)=\sqrt{\frac{1}{2} \sum_{i=1}^{n}\left[\left(\Delta_{t}(i)\right)^{2}+\left(\Delta_{f}(i)\right)^{2}\right]} \\
& d_{n E}^{\text {Ata }}(A, B)=\sqrt{\frac{1}{2 n} \sum_{i=1}^{n}\left[\left(\Delta_{t}(i)\right)^{2}+\left(\Delta_{f}(i)\right)^{2}\right]}
\end{aligned}
$$

However, in vague sets $A$ and $B, \Delta_{\pi}(i), \Delta_{t}(i)$, and $\Delta_{f}(i)$ have the following relations:

$$
\begin{gathered}
\left|\Delta_{\pi}(i)\right|=\left|\Delta_{t}(i)-\Delta_{f}(i)\right| \leq\left|\Delta_{t}(i)\right|+\left|\Delta_{f}(i)\right|, \\
\left(\Delta_{\pi}(i)\right)^{2}=\left(\Delta_{t}(i)\right)^{2}+\left(\Delta_{f}(i)\right)^{2}+2 \Delta_{t}(i) \cdot \Delta_{f}(i) .
\end{gathered}
$$

From (12), the distance $\left|\Delta_{\pi}(i)\right|$ between the degree of hesitation $\pi_{A}\left(x_{i}\right)$ and the degree of hesitation $\pi_{B}\left(x_{i}\right)$ is not strictly linear relations with the distances $\left|\Delta_{t}(i)\right|$ and $\left|\Delta_{f}(i)\right|$ when we use (11). Thus, the degree of hesitation $\pi_{A}\left(x_{i}\right)$ and the degree of hesitation $\pi_{B}\left(x_{i}\right)$ should not be omitted in distances between VSs. As a result, Szmidt and Kacprzyk [18] improved the Atanassov's distances between VSs.

(2) Szmidt and Kacprzyk's Distances between Vague Sets:

$$
\begin{aligned}
& d_{H}^{\mathrm{Sz}}(A, B)=\frac{1}{2} \sum_{i=1}^{n}\left[\left|\Delta_{t}(i)\right|+\left|\Delta_{f}(i)\right|+\left|\Delta_{\pi}(i)\right|\right], \\
& d_{n H}^{\mathrm{Sz}}(A, B)=\frac{1}{2 n} \sum_{i=1}^{n}\left[\left|\Delta_{t}(i)\right|+\left|\Delta_{f}(i)\right|+\left|\Delta_{\pi}(i)\right|\right], \\
& d_{E}^{\mathrm{Sz}}(A, B)=\sqrt{\frac{1}{2} \sum_{i=1}^{n}\left[\left(\Delta_{t}(i)\right)^{2}+\left(\Delta_{f}(i)\right)^{2}+\left(\Delta_{\pi}(i)\right)^{2}\right]}, \\
& d_{n E}^{\mathrm{Sz}}(A, B)=\sqrt{\frac{1}{2 n} \sum_{i=1}^{n}\left[\left(\Delta_{t}(i)\right)^{2}+\left(\Delta_{f}(i)\right)^{2}+\left(\Delta_{\pi}(i)\right)^{2}\right]} .
\end{aligned}
$$

In fact, formulas (13) are, respectively, the Hamming distances and the Euclidean distances between the vectors $\left(t_{A}\left(x_{i}\right), f_{A}\left(x_{i}\right), \pi_{A}\left(x_{i}\right)\right)$ and $\left(t_{B}\left(x_{i}\right), f_{B}\left(x_{i}\right), \pi_{B}\left(x_{i}\right)\right)$. Therefore, they satisfy the conditions of Definition 2. However, formulas (13) could not strictly satisfy the fourth condition in Definition 3, since $t_{A}\left(x_{i}\right), f_{A}\left(x_{i}\right)$ and $\pi_{A}\left(x_{i}\right)$ satisfy the condition $t_{A}\left(x_{i}\right)+f_{A}\left(x_{i}\right)+\pi_{A}\left(x_{i}\right)=1$ (see Example 4 ). To this end, we conduct a detailed analysis as follows.
Let vague values $A=\left[t_{A}, 1-f_{A}\right], B=\left[t_{B}, 1-f_{B}\right]$, and $C=\left[t_{C}, 1-f_{C}\right]$. If $A \subseteq B \subseteq C$, then $t_{A} \leq t_{B} \leq t_{C}$ and $f_{A} \geq f_{B} \leq f_{C}$, we get

$$
\begin{aligned}
\Delta_{t}^{A C} & \leq \Delta_{t}^{A B} \leq 0, \quad \Delta_{f}^{A C} \geq \Delta_{f}^{A B} \geq 0 \\
& \left|\Delta_{t}^{A B}\right| \leq\left|\Delta_{t}^{A C}\right|, \quad\left|\Delta_{f}^{A B}\right| \leq\left|\Delta_{f}^{A C}\right|,
\end{aligned}
$$

where $\Delta_{t}^{A B}=t_{A}-t_{B}, \Delta_{f}^{A B}=f_{A}-f_{B}$. But for $\Delta_{\pi}^{A B}=\pi_{A}-\pi_{B}$ and $\Delta_{\pi}^{A C}=\pi_{A}-\pi_{C}$, since

$$
\left|\Delta_{\pi}^{A B}\right|=\left|\Delta_{t}^{A B}+\Delta_{f}^{A B}\right|, \quad\left|\Delta_{\pi}^{A C}\right|=\left|\Delta_{t}^{A C}+\Delta_{f}^{A C}\right|
$$

So, from formulas (14) and (15), we cannot clear assert that $\left|\Delta_{\pi}^{A B}\right| \leq\left|\Delta_{\pi}^{A C}\right|$ or $\left|\Delta_{\pi}^{A B}\right| \geq\left|\Delta_{\pi}^{A C}\right|$. Thus, $d_{H}^{S z}(A, B) \leq d_{H}^{S z}(A, C)$ may not be true; that is, the distance $d_{H}^{\mathrm{Sz}}(A, B)$ may be improper. Similarly, $d_{n H}^{\mathrm{Sz}}(A, B), d_{E}^{\mathrm{Sz}}(A, B)$, and $d_{n E}^{\mathrm{Sz}}(A, B)$ are also improper; see Example 4.

The results of the above analysis show that there must be the relationship between $\left|\Delta_{\pi}^{A B}\right|$ and $\left|\Delta_{\pi}^{A C}\right|$ not determined if we introduce $\Delta_{\pi}(i)=\pi_{A}\left(x_{i}\right)-\pi_{B}\left(x_{i}\right)$ into distances between VSs directly. This is because $\pi_{A}\left(x_{i}\right)$ and $\pi_{B}\left(x_{i}\right)$ have no clear relationships when $A \subseteq B$ or $B \subseteq A$.

(3) Liu's Distances between Vague Sets. Liu proposed new distances between VSs based on the geometric interpretation of vague sets [13].

If $U$ is continuous, the distance between $A$ and $B$ is

$$
\begin{aligned}
& d^{\text {Liu }}(A, B) \\
& =\sqrt[p]{\frac{1}{2(b-a)} \int_{a}^{b}\left[\left(\Delta_{t}(i)\right)^{p}+\left(\Delta_{f}(i)\right)^{p}+\left(\Delta_{\pi}(i)\right)^{p}\right] d x .}
\end{aligned}
$$

If $U$ is discrete, the distance between $A$ and $B$ is

$$
d_{n E}^{\mathrm{Liu}}(A, B)=\sqrt[p]{\frac{1}{2 n} \sum_{i=1}^{n}\left[\left(\Delta_{t}(i)\right)^{p}+\left(\Delta_{f}(i)\right)^{p}+\left(\Delta_{\pi}(i)\right)^{p}\right]} .
$$

In (16) and (17), $1<p<+\infty$.

If $p=2$, Liu's method is Szmidt and Kacprzyk's normalized Euclidean distance. Thus, Liu's method may not satisfy the fourth condition in Definition 3.

\subsubsection{Distances between Vague Sets Based on Hausdorff Measure}

(1) Hung-Grzegorzewski-Chen's Distance between Vague Sets. Based on Hausdorff measure, Hung and Yang [20] and 
Grzegorzewski [21] defined the Hausdorff distances between vague sets, which are revised by Chen [22] as following:

$$
\begin{aligned}
& d_{H}^{\text {Hung }}(A, B)=\sum_{i=1}^{n} \max \left\{\left|\Delta_{t}(i)\right|,\left|\Delta_{f}(i)\right|\right\} \\
& d_{n H}^{\text {Hung }}(A, B)=\frac{1}{n} \sum_{i=1}^{n} \max \left\{\left|\Delta_{t}(i)\right|,\left|\Delta_{f}(i)\right|\right\} \\
& d_{E}^{\text {Hung }}(A, B)=\sqrt{\sum_{i=1}^{n} \max \left\{\left(\Delta_{t}(i)\right)^{2},\left(\Delta_{f}(i)\right)^{2}\right\}} \\
& d_{n E}^{\text {Hung }}(A, B)=\sqrt{\frac{1}{n} \sum_{i=1}^{n} \max \left\{\left(\Delta_{t}(i)\right)^{2},\left(\Delta_{f}(i)\right)^{2}\right\}} .
\end{aligned}
$$

Although formulas (18) satisfy the conditions of Definitions 2 and 3 , they all neglect the degree of hesitation $\pi_{A}\left(x_{i}\right)$ and the degree of hesitation $\pi_{B}\left(x_{i}\right)$. Yang and Chiclana [23] analyzed that it will obtain the inconsistent results when two of three objects $t\left(x_{i}\right), f\left(x_{i}\right)$, and $\pi\left(x_{i}\right)$ are only considered. For this reason, they proposed several distances between vague sets.

(2) Yang and Chiclana's Distances between Vague Sets:

$$
\begin{aligned}
& d_{H}^{\text {Yang }}(A, B)=\sum_{i=1}^{n} \max \left\{\left|\Delta_{t}(i)\right|,\left|\Delta_{f}(i)\right|,\left|\Delta_{\pi}(i)\right|\right\}, \\
& d_{n H}^{\text {Yang }}(A, B)=\frac{1}{n} \sum_{i=1}^{n} \max \left\{\left|\Delta_{t}(i)\right|,\left|\Delta_{f}(i)\right|,\left|\Delta_{\pi}(i)\right|\right\}, \quad \\
& d_{E}^{\text {Yang }}(A, B)=\sqrt{\sum_{i=1}^{n} \max \left\{\left(\Delta_{t}(i)\right)^{2},\left(\Delta_{f}(i)\right)^{2},\left(\Delta_{\pi}(i)\right)^{2}\right\}},
\end{aligned}
$$

$$
d_{n E}^{\text {Yang }}(A, B)=\sqrt{\frac{1}{n} \sum_{i=1}^{n} \max \left\{\left(\Delta_{t}(i)\right)^{2},\left(\Delta_{f}(i)\right)^{2},\left(\Delta_{\pi}(i)\right)^{2}\right\}}
$$

In 2013, Luo and Xiao [27] introduced the weights $\omega_{i}$ into formula (19) and obtained

$$
d_{H}^{\text {Luo }}(A, B)=\sum_{i=1}^{n} \omega_{i} \cdot \max \left\{\left|\Delta_{t}(i)\right|,\left|\Delta_{f}(i)\right|,\left|\Delta_{\pi}(i)\right|\right\},
$$

where $\sum_{i=1}^{n} \omega_{i}=1,0 \leq \omega_{i} \leq 1$. Particularly, if $\omega_{i}=$ $(1 / n)(i=1,2, \ldots, n)$, then formula (23) will be formula (20). Luo and Xiao proved in detail that formula (23) satisfies all the conditions of Definition 3. But formulas (21) and (22) may not satisfy the fourth condition of Definition 3.

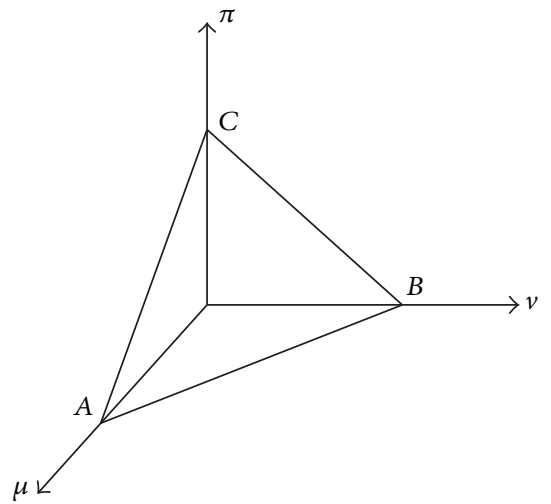

FIGURE 1: Geometrical interpretation of vague sets.

3.2.4. Other Distances. According to Definition 3, Wang and Xin [25] defined the distances between vague sets; that is,

$$
\begin{aligned}
& d^{\text {Wang }}(A, B) \\
& =\frac{1}{n} \sum_{i=1}^{n}\left[\frac{\left|\Delta_{t}(i)\right|+\left|\Delta_{f}(i)\right|}{4}+\frac{\max \left\{\left|\Delta_{t}(i)\right|,\left|\Delta_{f}(i)\right|\right\}}{2}\right], \\
& d_{\omega}^{\text {Wang }}(A, B) \\
& =\sum_{i=1}^{n} \omega_{i}\left(\left[\left(\left|\Delta_{t}(i)\right|+\left|\Delta_{f}(i)\right|\right) / 4\right.\right. \\
& \left.\left.\quad+\max \left\{\left|\Delta_{t}(i)\right|,\left|\Delta_{f}(i)\right|\right\} / 2\right]\right) \\
& \times\left(\sum_{i=1}^{n} \omega_{i}\right)^{-1}, \\
& d_{p}^{\text {Wang }}(A, B)=\sqrt[p]{\frac{1}{n} \sum_{i=1}^{n}\left(\frac{\left|\Delta_{t}(i)\right|+\left|\Delta_{f}(i)\right|}{2}\right)^{p} .}
\end{aligned}
$$

If $p=1, d_{p}^{\text {Wang }}(A, B)$ is $d_{n H}^{\text {Ata }}(A, B)$; if $p=2, d_{p}^{\text {Wang }}(A, B)$ is $d_{n E}^{\text {Ata }}(A, B)$. Thus, Wang and Xin's method also has the same deficiencies as Atanassov's distances between vague sets.

The deficiencies of the above-mentioned methods will be illustrated by Example 4 .

Example 4. Let $A=[1,1], B=[0,0]$, and $C=[0,1]$ be the three vague values. Since $B \subset C \subset A$, the distance between $A$ and $B$ is difference from the distance between $A$ and $C$. The geometrical interpretation of vague sets $A, B$, and $C$ is presented in Figure 1. The results of the above-mentioned distances between vague sets $A, B$, and $C$ are shown in Table 1 .

From Table 1 , the methods $d_{H}^{\text {Ata }}, d_{E}^{\text {Ata }}, d^{\text {Wang }}$, and $d_{p}^{\text {Wang }}(p=2)$ can get $d(A, B)>d(A, C)=d(B, C)$, but other methods do not. However, the degree of hesitation $\pi\left(x_{i}\right)$ is not considered in the methods $d_{H}^{\text {Ata }}, d_{E}^{\text {Ata }}, d^{\text {Wang }}$, and $d_{p}^{\text {Wang }}$. 
TABLE 1: The results of existing distances between vague sets $A, B$, and $C$.

\begin{tabular}{lccc}
\hline Distance between VSs & $\begin{array}{c}A=[1,1], B=[0,0] \\
d(A, B)\end{array}$ & $\begin{array}{c}A=[1,1], C=[0,1] \\
d(A, C)\end{array}$ & $\begin{array}{c}B=[0,0], C=[0,1] \\
d(B, C)\end{array}$ \\
\hline$d_{H}^{\text {Ata }}$ & 1.0 & 0.5 & 0.5 \\
$d_{E}^{\text {Ata }}$ & 1.0 & $\sqrt{1 / 2}$ & $\mathbf{1 . 0}$ \\
$d_{H}^{\text {Sz }}$ & $\mathbf{1 . 0}$ & $\mathbf{1 . 0}$ & $\mathbf{1 . 0}$ \\
$d_{E}^{\text {Sz }}$ & $\mathbf{1 . 0}$ & $\mathbf{1 . 0}$ & $\mathbf{1 . 0}$ \\
$d_{n E}^{\text {Liu }}(p=2)$ & $\mathbf{1 . 0}$ & $\mathbf{1 . 0}$ & $\mathbf{1 . 0}$ \\
$d_{H}^{\text {Hung }}$ & $\mathbf{1 . 0}$ & $\mathbf{1 . 0}$ & $\mathbf{1 . 0}$ \\
$d_{E}^{\text {Hung }}$ & $\mathbf{1 . 0}$ & $\mathbf{1 . 0}$ & $\mathbf{1 . 0}$ \\
$d_{H}^{\text {Yang }}$ & $\mathbf{1 . 0}$ & $\mathbf{1 . 0}$ & $\mathbf{1 . 0}$ \\
$d_{E}^{\text {Yang }}$ & $\mathbf{1 . 0}$ & $\mathbf{1 . 0}$ & $\mathbf{1 . 0}$ \\
$d_{H}^{\text {Luo }}$ & $\mathbf{1 . 0}$ & $\mathbf{1 . 0}$ & 0.75 \\
$d^{\text {Wang }}$ & 1.0 & 0.75 & $\sqrt{1 / 2}$ \\
$d_{p}^{\text {Wang }}(p=2)$ & 1.0 & $\sqrt{1 / 2}$ & \\
\hline
\end{tabular}

Based on the analysis in Table 1, we think that the degree of membership, nonmembership, and hesitation should be introduced into the distance measures between vague sets, and the distances between vague sets must satisfy Definitions 2 and 3. For this reason, we propose a new distance which will be a detailed introduction in Section 4.

\section{A New Distance between Vague Sets and Its Analysis}

Let $U=\left\{x_{1}, x_{2}, \ldots, x_{n}\right\}$ be objects set of $n$ experts who vote for or against a given decision. The degree of each expert $x_{i}$ voting in favor is $t_{A}\left(x_{i}\right)$, voting against is $f_{A}\left(x_{i}\right)$, and the hesitation is $\pi_{A}\left(x_{i}\right)$. For example, suppose that the expert $x_{i}$ at the beginning of negotiations voting in favor is $t_{A}\left(x_{i}\right)=0.6$ and against is $f_{A}\left(x_{i}\right)=0.2$, which means $\pi_{A}\left(x_{i}\right)=0.2$. If we persuade that he should vote for, then the best result is $t_{A+\text { final }}\left(x_{i}\right)=t_{A}\left(x_{i}\right)+\pi_{A}\left(x_{i}\right)=0.8$ with $f_{A+f i n a l}\left(x_{i}\right)=0.2$. On the contrary, if he votes against, then the best result that the opponents can achieve is $f_{A+\text { final }}\left(x_{i}\right)=f_{A}\left(x_{i}\right)+\pi_{A}\left(x_{i}\right)=$ 0.4 with $t_{A+\text { final }}\left(x_{i}\right)=0.6$. It may happen that $t_{A+\text { final }}\left(x_{i}\right)$ could be any number from $[0.6,0.8]$ and $f_{A+\text { final }}\left(x_{i}\right)$ may be any number from $[0.2,0.4]$. Therefore, we should consider the assignment of $\pi_{A}\left(x_{i}\right)$ to $t_{A}\left(x_{i}\right)$ and $f_{A}\left(x_{i}\right)$ separately if $\pi_{A}\left(x_{i}\right)$ is introduced into the distances between VSs; that is, we investigate the influence of hesitation degree $\pi_{A}\left(x_{i}\right)$ to the distances between VSs indirectly.

Let $A=\left[t_{A}(x), 1-f_{A}(x)\right]$ be a vague value; the assignment of $\pi_{A}(x)$ to $t_{A}(x)$ and $f_{A}(x)$ is defined as $\omega^{\pi t}\left(\pi_{A}(x)+\right.$ $\left.2 t_{A}(x)\right)$ and $\omega^{\pi f}\left(\pi_{A}(x)+2 f_{A}(x)\right)$, respectively, where $\omega^{\pi t}$ and $\omega^{\pi f}$ represent the weights. Thus, for each vague value $A$, there will be four parts: $t_{A}(x), f_{A}(x), \omega^{\pi t}\left(\pi_{A}(x)+2 t_{A}(x)\right)$, and $\omega^{\pi f}\left(\pi_{A}(x)+2 f_{A}(x)\right)$. A new distance between vague values, denoted as $d_{\mathrm{VVs}}$, can be defined as follows.
Definition 5. Let $A=\left[t_{A}(x), 1-f_{A}(x)\right]$ and $B=\left[t_{B}(x), 1-\right.$ $f_{B}(x)$ ] be two vague values; then the distance between $A$ and $B$ is defined as

$$
\begin{aligned}
& d_{\mathrm{VVs}}(A, B) \\
& =\frac{\left(\left|\Delta_{t}\right|+\left|\Delta_{f}\right|+\omega^{\pi t} \cdot\left|\Delta_{\pi}+2 \Delta_{t}\right|+\omega^{\pi f} \cdot\left|\Delta_{\pi}+2 \Delta_{f}\right|\right)}{4},
\end{aligned}
$$

where $\Delta_{\pi}+2 \Delta_{t}$ and $\Delta_{\pi}+2 \Delta_{f}$ represent the assignments of $\Delta_{\pi}$ to $\Delta_{t}$ and $\Delta_{f}$, respectively. $\omega^{\pi t} \geq 0$ and $\omega^{\pi f} \geq 0$ represent the assigned weights of $\Delta_{\pi}$ to $\Delta_{t}$ and $\Delta_{f}$, respectively, and satisfy $\omega^{\pi t}+\omega^{\pi f}=1$.

For Example 4, we can get $d_{\mathrm{VVs}}(A, B)=1$ and $d_{\mathrm{VVs}}(A, C)=d_{\mathrm{VVs}}(C, B)=0.5$, where $\omega^{\pi t}=\omega^{\pi f}=0.5$, same applies hereinafter, and we can prove that $d_{\mathrm{VVs}}$ is a distance measure that satisfied Definitions 2 and 3.

Theorem 6. Let $A=\left[t_{A}(x), 1-f_{A}(x)\right]$ and $B=\left[t_{B}(x), 1-\right.$ $f_{B}(x)$ ] be two vague values; then $d_{V V s}(A, B)$ is a distance measure between $A$ and $B$ and satisfies Definitions 2 and 3.

Proof. (1) From formula (25), $d_{\mathrm{VVs}}(A, B) \geq 0$. In addition, $\left|\Delta_{t}\right| \leq 1,\left|\Delta_{f}\right| \leq 1$ and $\left|\Delta_{\pi}+2 \Delta_{t}\right| \leq\left|\Delta_{t}\right|+\left|\Delta_{f}\right| \leq 2$. Similarly, $\left|\Delta_{\pi}+2 \Delta_{f}\right| \leq 2$. Thus, $d_{\mathrm{VVs}}(A, B) \leq 1$. That is, $d_{\mathrm{VVs}}(A, B)$ satisfies condition (1) in Definition 3.

(2) If $A=B$, then $\Delta_{t}=\Delta_{f}=\Delta_{\pi}=0$; thereby, $d_{\mathrm{VVs}}(A, B)=0$.

Conversely, if $d_{\mathrm{VVs}}(A, B)=0$, then $\Delta_{t}=\Delta_{f}=0$; accordingly, $\Delta_{\pi}=0$; that is, $A=B$.

Thus, $d_{\mathrm{VVs}}(A, B)$ satisfies condition (1) in Definition 2 and condition (2) in Definition 3.

(3) From formula (25), $d_{\mathrm{VVs}}(A, B)=d_{\mathrm{VVs}}(B, A)$. So, $d_{\mathrm{VVs}}(A, B)$ satisfies condition (2) in Definition 2 and condition (3) in Definition 3. 
(4) If $C=\left[t_{C}(x), 1-f_{C}(x)\right]$, we have

$$
\begin{gathered}
\left|\Delta_{t}^{A C}\right|=\left|\Delta_{t}^{A B}+\Delta_{t}^{B C}\right| \leq\left|\Delta_{t}^{A B}\right|+\left|\Delta_{t}^{B C}\right|, \\
\left|\Delta_{f}^{A C}\right|=\left|\Delta_{f}^{A B}+\Delta_{f}^{B C}\right| \leq\left|\Delta_{f}^{A B}\right|+\left|\Delta_{f}^{B C}\right|, \\
\omega^{\pi t} \cdot\left|\Delta_{\pi}^{A C}+2 \Delta_{t}^{A C}\right| \\
=\omega^{\pi t} \cdot\left|\Delta_{\pi}^{A B}+\Delta_{\pi}^{B C}+2\left(\Delta_{t}^{A B}+\Delta_{t}^{B C}\right)\right| \\
\leq \omega^{\pi t} \cdot\left|\Delta_{\pi}^{A B}+2 \Delta_{t}^{A B}\right|+\omega^{\pi t} \cdot\left|\Delta_{\pi}^{B C}+2 \Delta_{t}^{B C}\right|, \\
\omega^{\pi f} \cdot\left|\Delta_{\pi}^{A C}+2 \Delta_{f}^{A C}\right| \\
=\omega^{\pi f} \cdot\left|\Delta_{\pi}^{A B}+\Delta_{\pi}^{B C}+2\left(\Delta_{f}^{A B}+\Delta_{f}^{B C}\right)\right| \\
\leq \omega^{\pi f} \cdot\left|\Delta_{\pi}^{A B}+2 \Delta_{f}^{A B}\right|+\omega^{\pi f} \cdot\left|\Delta_{\pi}^{B C}+2 \Delta_{f}^{B C}\right| .
\end{gathered}
$$

Thus, $d_{\mathrm{VVs}}(A, B)+d_{\mathrm{VVs}}(B, C) \geq d_{\mathrm{VVs}}(A, C)$, which shows that condition (3) in Definition 2 is satisfied.

(5) If $A \subseteq B \subseteq C$, then $0 \leq t_{A} \leq t_{B} \leq t_{C}$ and $f_{A} \geq f_{B} \geq$ $f_{C} \geq 0$, we have

$$
\begin{aligned}
\Delta_{t}^{A C} \leq \Delta_{t}^{A B} \leq 0, & \quad \Delta_{f}^{A C} \geq \Delta_{f}^{A B} \geq 0 \\
\left|\Delta_{f}^{A B}\right| \leq\left|\Delta_{f}^{A C}\right|, & \quad\left|\Delta_{t}^{A B}\right| \leq\left|\Delta_{t}^{A C}\right| ; \\
\omega^{\pi t} \cdot\left|\Delta_{\pi}^{A B}+2 \Delta_{t}^{A B}\right| & =\omega^{\pi t} \cdot\left|\Delta_{f}^{A B}-\Delta_{t}^{A B}\right| \\
& \leq \omega^{\pi t} \cdot\left|\Delta_{t}^{A C}-\Delta_{f}^{A C}\right| \\
& =\omega^{\pi t} \cdot\left|\Delta_{\pi}^{A C}+2 \Delta_{t}^{A C}\right| ; \\
\omega^{\pi f} \cdot\left|\Delta_{\pi}^{A B}+2 \Delta_{f}^{A B}\right| & =\omega^{\pi f} \cdot\left|\Delta_{f}^{A B}-\Delta_{t}^{A B}\right| \\
& \leq \omega^{\pi f} \cdot\left|\Delta_{f}^{A C}-\Delta_{t}^{A C}\right| \\
& =\omega^{\pi f} \cdot\left|\Delta_{\pi}^{A C}+2 \Delta_{f}^{A C}\right| .
\end{aligned}
$$

Thus, $d_{\mathrm{VVs}}(A, B) \leq d_{\mathrm{VVs}}(A, C)$.

Similarly, $d_{\mathrm{VVs}}(B, C) \leq d_{\mathrm{VVs}}(A, C)$. This result shows that condition (4) in Definition 3 is satisfied.

Therefore, the above proof shows that $d_{\mathrm{VVs}}(A, B)$ is a distance measure between $A$ and $B$ and satisfies Definitions 2 and 3.

Definition 7. Let $A, B$ be two VSs in $U=\left\{x_{1}, x_{2}, \ldots, x_{n}\right\}$; then the distance measure between vague sets $A$ and $B$, denoted as $d_{\mathrm{VSs}}$, is defined as

$$
\begin{aligned}
d_{\mathrm{VSs}}(A, B)=\frac{1}{4 n} \sum_{i=1}^{n}( & \left|\Delta_{t}(i)\right|+\left|\Delta_{f}(i)\right|+\omega^{\pi t}(i) \\
\cdot & \left|\Delta_{\pi}(i)+2 \Delta_{t}(i)\right| \\
& \left.+\omega^{\pi f}(i) \cdot\left|\Delta_{\pi}(i)+2 \Delta_{f}(i)\right|\right),
\end{aligned}
$$

where $\omega^{\pi t}(i)+\omega^{\pi f}(i)=1\left(\omega^{\pi t}(i), \omega^{\pi f}(i) \geq 0, i=1,2, \ldots, n\right)$. $\omega^{\pi t}(i)$ and $\omega^{\pi f}(i)$ represent the assigned weights of $\Delta_{\pi}(i)$ to $\Delta_{t}(i)$ and $\Delta_{f}(i)$, respectively.

Theorem 8. $d_{V S s}(A, B)$ is a distance measure between $A$ and $B$ in $U=\left\{x_{1}, x_{2}, \ldots, x_{n}\right\}$ and satisfies Definitions 2 and 3.

Proof. Similar to the proof of Theorem 6 (omitted).

\section{Comparative Analysis of the Experiment and Its Application in Multicriteria Fuzzy Decision Making}

To study the ability of the proposed metric to count the distance between two VSs, two experiments have been conducted: (1) pattern classification and (2) multicriteria fuzzy decision.

5.1. A Numerical Example for Pattern Classification. Assume that the question which relates to classification is given using VSs. Liang and Shi [28] use the principle of the maximum degree of similarity between VSs to solve the problem of pattern classification. Similarly, we use the principle of minimum distance between VSs to solve the problem. We use the classification data about building materials given by Wang and Xin [25]. Given four classes of building material, each is represented by the vague sets $C_{1}, C_{2}, C_{3}$, and $C_{4}$ in the feature space $U=\left\{x_{1}, x_{2}, \ldots, x_{12}\right\}$; see Table 2 . Now, given another kind of unknown building material $S$, we justify which class the $S$ belongs to through computing the distance between $S$ and each $C_{i}(i=1,2,3,4)$. The $S$ belongs to the class $C_{i}$ when the distance between $S$ and each $C_{i}$ is minimal among the distances between $S$ and each $C_{i}(i=1,2,3,4)$.

The classification performance is illustrated by the degree of confidence (DOC) proposed by Hatzimichailidis et al. [24]. This factor measures the confidence of each distance metric in recognizing a specific sample that belongs to the class $(j)$ and has the following form:

$$
\operatorname{DOC}^{(j)}=\sum_{i=1, i \neq j}^{n}\left|d\left(C_{j}, S\right)-d\left(C_{i}, S\right)\right| .
$$

Obviously, the greater $\mathrm{DOC}^{(j)}$ is, the more confident the result of the specific distance metric is.

Table 3 summarizes the distance measures' results along with the degree of confidence of each one among the above distances between VSs that we have introduced. In Table 3, the minimum distance and the best results with the highest degree of confidence have been denoted in bold. All the distances can classify the test sample correctly. However, the existing distance measures fail to introduce the degree of hesitation into the distance measure between VSs which causes the DOC to be lower, while the proposed method has higher DOC. Thus, the results of classification indicate that our method is effective.

5.2. Presentation of Multicriteria Fuzzy Decision Based on the Distance Measures between VSs. Let $\mathbf{A}=\left\{A_{1}, A_{2}, \ldots, A_{m}\right\}$ 
TABle 2: 4 Classes/12-feature problem and test sample.

\begin{tabular}{|c|c|c|c|c|c|c|c|c|c|c|c|c|c|}
\hline \multirow{2}{*}{\multicolumn{2}{|c|}{ Classes }} & \multicolumn{12}{|c|}{ Features } \\
\hline & & $x_{1}$ & $x_{2}$ & $x_{3}$ & $x_{4}$ & $x_{5}$ & $x_{6}$ & $x_{7}$ & $x_{8}$ & $x_{9}$ & $x_{10}$ & $x_{11}$ & $x_{12}$ \\
\hline \multirow{2}{*}{$C_{1}$} & $t_{C_{1}}(x)$ & 0.173 & 0.102 & 0.530 & 0.965 & 0.420 & 0.008 & 0.331 & 1.000 & 0.215 & 0.432 & 0.750 & 0.432 \\
\hline & $f_{C_{1}}(x)$ & 0.524 & 0.818 & 0.326 & 0.008 & 0.351 & 0.956 & 0.512 & 0.000 & 0.625 & 0.534 & 0.126 & 0.432 \\
\hline \multirow{2}{*}{$C_{2}$} & $t_{C_{2}}(x)$ & 0.510 & 0.627 & 1.000 & 0.125 & 0.026 & 0.732 & 0.556 & 0.650 & 1.000 & 0.145 & 0.047 & 0.760 \\
\hline & $f_{C_{2}}(x)$ & 0.365 & 0.125 & 0.000 & 0.648 & 0.823 & 0.153 & 0.303 & 0.267 & 0.000 & 0.762 & 0.923 & 0.231 \\
\hline \multirow{2}{*}{$C_{3}$} & $t_{C_{3}}(x)$ & 0.495 & 0.603 & 0.987 & 0.073 & 0.037 & 0.690 & 0.147 & 0.213 & 0.501 & 1.000 & 0.324 & 0.045 \\
\hline & $f_{C_{3}}(x)$ & 0.387 & 0.298 & 0.006 & 0.849 & 0.923 & 0.268 & 0.812 & 0.653 & 0.284 & 0.000 & 0.483 & 0.912 \\
\hline \multirow{2}{*}{$C_{4}$} & $t_{C_{4}}(x)$ & 1.000 & 1.000 & 0.857 & 0.734 & 0.021 & 0.076 & 0.152 & 0.113 & 0.489 & 1.000 & 0.386 & 0.028 \\
\hline & $f_{C_{4}}(x)$ & 0.000 & 0.000 & 0.123 & 0.158 & 0.896 & 0.912 & 0.712 & 0.756 & 0.389 & 0.000 & 0.485 & 0.912 \\
\hline \multirow{2}{*}{$S$} & $t_{S}(x)$ & 0.978 & 0.980 & 0.798 & 0.693 & 0.051 & 0.123 & 0.152 & 0.113 & 0.494 & 0.987 & 0.376 & 0.012 \\
\hline & $f_{S}(x)$ & 0.003 & 0.012 & 0.132 & 0.213 & 0.876 & 0.756 & 0.721 & 0.732 & 0.368 & 0.000 & 0.423 & 0.897 \\
\hline
\end{tabular}

TABLE 3: Distances results.

\begin{tabular}{|c|c|c|c|c|c|}
\hline \multirow{2}{*}{ Distances } & \multicolumn{5}{|c|}{ Results } \\
\hline & $d\left(C_{1}, S\right)$ & $d\left(C_{2}, S\right)$ & $d\left(C_{3}, S\right)$ & $d\left(C_{4}, S\right)$ & $\operatorname{DOC}^{(4)}$ \\
\hline$d_{n H}^{\mathrm{Ata}}(A, B)$ & 0.4311 & 0.4362 & 0.1982 & 0.0270 & 0.9845 \\
\hline$d_{n E}^{\mathrm{Ata}}(A, B)$ & 0.4910 & 0.4865 & 0.2920 & 0.0423 & 1.1426 \\
\hline$d_{n H}^{\mathrm{Sz}}(A, B)$ & 0.4764 & 0.4857 & 0.2246 & 0.0427 & 1.0586 \\
\hline$d_{n E}^{\mathrm{Sz}}(A, B)$ & 0.4978 & 0.4935 & 0.2953 & 0.0521 & 1.1303 \\
\hline$d_{n E}^{\mathrm{Liu}}(A, B)(p=2)$ & 0.4978 & 0.4935 & 0.2953 & 0.0521 & 1.1303 \\
\hline$d_{n E}^{\mathrm{Liu}}(A, B)(p=3)$ & 0.5446 & 0.5229 & 0.3531 & 0.0648 & 1.2262 \\
\hline$d_{n H}^{\text {Hung }}(A, B)$ & 0.4764 & 0.4837 & 0.2233 & 0.0406 & 1.0616 \\
\hline$d_{n E}^{\text {Hung }}(A, B)$ & 0.5364 & 0.5259 & 0.3122 & 0.0563 & 1.2056 \\
\hline$d_{n H}^{\text {Yang }}(A, B)$ & 0.4501 & 0.4659 & 0.2050 & 0.0219 & 1.0553 \\
\hline$d_{n E}^{\text {Yang }}(A, B)$ & 0.6419 & 0.6375 & 0.4374 & 0.1794 & 1.1786 \\
\hline $\begin{array}{l}d_{H}^{\text {Luo }}(A, B) \\
\left(\omega_{1}=\cdots=\omega_{4}=0.25\right)\end{array}$ & 0.4501 & 0.4659 & 0.2050 & 0.0219 & 1.0553 \\
\hline$d^{\text {Wang }}(A, B)$ & 0.4537 & 0.4599 & 0.2107 & 0.0338 & 1.0229 \\
\hline$d_{1}^{\text {Wang }}(A, B)$ & 0.4311 & 0.4362 & 0.1982 & 0.0270 & 0.9845 \\
\hline$d_{2}^{\text {Wang }}(A, B)$ & 0.4876 & 0.4831 & 0.2904 & 0.0373 & 1.1492 \\
\hline$d_{\mathrm{VSs}}(A, B)$ & 0.6566 & 0.6596 & 0.4445 & 0.1612 & 1.2769 \\
\hline
\end{tabular}

be the set of alternatives and let $\omega_{1}, \omega_{2}, \ldots, \omega_{n}$ be the corresponding weights of the criteria $\mathbf{C}=\left\{C_{1}, C_{2}, \ldots, C_{n}\right\}$, where $\omega_{1}, \omega_{2}, \ldots, \omega_{n} \in[0,1]$ and $\sum_{i=1}^{n} \omega_{i}=1$. The characteristic of the alternative $A_{i}$ is represented by a vague set:

$$
\begin{aligned}
A_{i}=\{ & \left(C_{1},\left[t_{i 1}, 1-f_{i 1}\right]\right),\left(C_{2},\left[t_{i 2}, 1-f_{i 2}\right]\right), \ldots, \\
& \left.\left(C_{n},\left[t_{i n}, 1-f_{i n}\right]\right)\right\}
\end{aligned}
$$

where $0 \leq t_{i j}+f_{i j} \leq 1,1 \leq i \leq m$, and $1 \leq j \leq n$. $t_{i j}$ indicates the degree of the alternative $A_{i}$ which satisfies the criterion $C_{j}$ and $f_{i j}$ indicates the degree of the alternative $A_{i}$ which does not satisfy the criterion $C_{j}$ given by the decision maker.

The same as the TOPSIS method proposed by Hwang and Yoon [29], the best alternative is obtained by the minimum value $W_{C}\left(A_{i}\right)(i=1,2, \ldots, m)$, where $W_{C}\left(A_{i}\right)$ represents the weighted sum of the distance between $A_{i j}$ and $I_{i}$; namely,

$$
\begin{aligned}
W_{\mathrm{C}}\left(A_{i}\right)= & d_{\mathrm{VSs}}\left(A_{i 1}, I_{1}\right) \times \omega_{1}+d_{\mathrm{VSs}}\left(A_{i 2}, I_{2}\right) \\
& \times \omega_{2}+\cdots+d_{\mathrm{VSs}}\left(A_{i n}, I_{n}\right) \times \omega_{n},
\end{aligned}
$$

where the vague set $A_{i j}=\left[t_{i j}, 1-f_{i j}\right]$ represents the characteristic of the alternative $A_{i}$ about the criterion $C_{j}$ and $I_{j}$ represents an idea alternative about the criterion $C_{j}(i=$ $1,2, \ldots, m ; j=1,2, \ldots, n)$ and is determined by the following expression:

$$
\begin{aligned}
I_{j}= & {\left[t_{1 j}, 1-f_{1 j}\right] \vee(\wedge)\left[t_{2 j}, 1-f_{2 j}\right] } \\
& \vee(\wedge) \cdots \vee(\wedge)\left[t_{m j}, 1-f_{m j}\right] \quad(j=1,2, \ldots, n),
\end{aligned}
$$

where the operators " $\vee$ " and " $\wedge$ " depend on the criterion $C_{j}$. 
With regard to the choice of weights $\omega_{1}, \omega_{2}, \ldots, \omega_{n}$, many researchers give a certain number between 0 and $1[13,30-$ 32]. In the paper, we use the optimal method to determine the weights $\omega_{1}, \omega_{2}, \ldots, \omega_{n}$ based on [11,33]. Namely, the optimal weights $\omega_{1}, \omega_{2}, \ldots, \omega_{n}$ satisfy

$$
\begin{aligned}
\min =\sum_{i=1}^{m}\left(d_{\mathrm{VSs}}\right. & \left(A_{i 1}, I_{1}\right) \times \omega_{1}+d_{\mathrm{VSs}}\left(A_{i 2}, I_{2}\right) \\
& \left.\times \omega_{2}+\cdots+d_{\mathrm{VSs}}\left(A_{i n}, I_{n}\right) \times \omega_{n}\right) ;
\end{aligned}
$$

s.t. $\quad \omega_{1}^{l} \leq \omega_{1} \leq \omega_{1}^{r}$;

$\omega_{2}^{l} \leq \omega_{2} \leq \omega_{2}^{r}$;

$$
\begin{aligned}
& \omega_{n}^{l} \leq \omega_{n} \leq \omega_{n}^{r} ; \\
& \sum_{i=1}^{n} \omega_{i}=1,
\end{aligned}
$$

where $\omega_{j}^{l}=\rho_{j}, \omega_{j}^{r}=1-\tau_{j}, \rho_{j}$ and $\tau_{j}$ indicate the degree of membership and nonmembership with respect to the criterion $C_{j}$ to the fuzzy concept "importance," respectively, and $0 \leq \rho_{j}, \tau_{j} \leq 1$ as well as $0 \leq \rho_{j}+\tau_{j} \leq 1$; that is, the weight $\omega_{j}$ is also expressed by a vague set $\left[\rho_{j}, 1-\tau_{j}\right]$, and $\xi_{j}=1-\rho_{j}-\tau_{j}$ indicates the degree of hesitation. In this way, the weight $\omega_{j}$ of the criterion $C_{j}$ is expressed by a closed interval $\left[\omega_{j}^{l}, \omega_{j}^{r}\right]=\left[\rho_{j}, \rho_{j}+\xi_{j}\right]$. In addition, suppose that $\omega_{1}^{l}+\omega_{2}^{l}+\cdots+\omega_{n}^{l} \leq 1$ and $\omega_{1}^{r}+\omega_{2}^{r}+\cdots+\omega_{n}^{r} \geq 1$ so that the expressions $\omega_{j}^{l} \leq \omega_{j} \leq \omega_{j}^{r}$ and $\sum_{i=1}^{n} \omega_{i}=1$ are valid.

5.3. A Numerical Example for Multicriteria Fuzzy Decision. We use the example given by $\mathrm{Li}$ [33]: an air-condition system selection problem. Suppose that there exist three aircondition systems $A_{1}, A_{2}$, and $A_{3}$. Denote the alternative set by $\mathbf{A}=\left\{A_{1}, A_{2}, A_{3}\right\}$. Suppose that there are three criteria $C_{1}$ (economical), $C_{2}$ (function), and $C_{3}$ (being operative) taken into consideration in the selection problem. Denote the set of all criteria by $\mathbf{C}=\left\{C_{1}, C_{2}, C_{3}\right\}$, and $\omega_{1}, \omega_{2}, \omega_{3}$ are the weights corresponding to $C_{1}, C_{2}, C_{3}$. Using statistical methods, the degrees $t_{i j}$ of membership and the degrees $f_{i j}(i, j=1,2,3)$ of nonmembership for the alternative $A_{i}$ with respect to the criterion $C_{j}$ to the fuzzy concept "excellence" can be obtained, respectively. Namely,

$$
\begin{aligned}
& \left(\left[t_{i j}, 1-f_{i j}\right]\right)= \\
& A_{1} \quad A_{2} \quad A_{3} \\
& \left.\begin{array}{llll}
C_{1} & ([0.75,0.90] & {[0.80,0.85]} & {[0.40,0.55]} \\
C_{2} & (0.60,0.75] & {[0.68,0.80]} & {[0.75,0.95]}
\end{array}\right) \\
& C_{3}([0.80,0.80][0.45,0.50][0.60,0.70])
\end{aligned}
$$

Similarly, the degrees $\rho_{j}$ of membership and the degrees $\tau_{j}(j=1,2,3)$ of nonmembership for the three criteria
$C_{1}, C_{2}, C_{3}$ to the fuzzy concept "importance" can be obtained, respectively; that is,

$$
\left(\left[\rho_{j}, 1-\tau_{j}\right]\right)=\begin{array}{ccc}
C_{1} & C_{2} & C_{3} \\
([0.25,0.75] & {[0.35,0.60]} & [0.30,0.35])
\end{array} .
$$

From (32), where the operator " $\mathrm{V}$ " is used, we get $I_{1}=$ $[0.80,0.9], I_{2}=[0.75,0.95]$, and $I_{3}=[0.80,0.80]$.

Based on (33) and the distance $d_{\mathrm{VSs}}$, we have

$$
\begin{array}{ll}
\min = & 0.4250 \omega_{1}+0.2850 \omega_{2}+0.4750 \omega_{3} ; \\
\text { s.t. } & 0.25 \leq \omega_{1} \leq 0.75 ; \\
& 0.35 \leq \omega_{2} \leq 0.60 ; \\
& 0.30 \leq \omega_{3} \leq 0.35 ; \\
& \omega_{1}+\omega_{2}+\omega_{3}=1 .
\end{array}
$$

The optimal solution is $\min =0.2513$, when $\omega_{1}=0.25$, $\omega_{2}=0.45$, and $\omega_{3}=0.30$.

According to (31), we obtain

$$
\begin{aligned}
& W_{C}\left(A_{1}\right)=0.0850, \\
& W_{C}\left(A_{2}\right)=0.1533, \\
& W_{C}\left(A_{3}\right)=0.1388 .
\end{aligned}
$$

Therefore, the minimum value is $W_{C}\left(A_{1}\right)=0.0850$. Namely, the best alternative is $A_{1}$. The optimal ranking order of the alternatives is given by $A_{1}>A_{3}>A_{2}$, which is consistent with the results of Xu and Wei [11] and Li [33]. However, the method is more concise than Li's method.

\section{Conclusions}

In this paper, we give a novel distance between vague sets, which considers the assignment of hesitancy degree $\pi(x)$ to the membership $t(x)$ and nonmembership degree $f(x)$, after analyzing the existing method, and the properties are also discussed. The performances of the proposed method are illustrated by pattern classification. Finally, our method is applied into multicriteria fuzzy decision making, where we take the linear programming method to generate optimal weights for every criteria and the best alternative is obtained by the weighted sum of distance measures between each alternative and the idea alternative with respect to a set of criteria. The experimental results demonstrate the effectiveness of the proposed method.

\section{Conflict of Interests}

The authors declare that there is no conflict of interests regarding the publication of this paper.

\section{Acknowledgments}

This work is supported by the National Natural Science Foundation of China (NSFC) under Grant 61309014, Natural 
Science Foundation Project of CQ CSTC under Grant nos. cstc2012jjA40032 and cstc2013jcyjA40063, Chongqing Key Lab of Computer Network and Communication Technology under Grant CY-CNCL-2010-05, and Chongqing Key Laboratory of Computational Intelligence under Grant CQLCI2013-08.

\section{References}

[1] L. A. Zadeh, "Fuzzy sets," Information and Control, vol. 8, no. 3, pp. 338-353, 1965.

[2] R. J. Li, Theories and Application of Multi-Criteria Decision Making, Science Press, Beijing, China, 2002, (Chinese).

[3] K. T. Atanassov, "Intuitionistic fuzzy sets," Fuzzy Sets and Systems, vol. 20, no. 1, pp. 87-96, 1986.

[4] W.-L. Gau and D. J. Buehrer, "Vague sets," IEEE Transactions on Systems, Man and Cybernetics, vol. 23, no. 2, pp. 610-614, 1993.

[5] H. Bustince and P. Burillo, "Vague sets are intuitionistic fuzzy sets," Fuzzy Sets and Systems, vol. 79, no. 3, pp. 403-405, 1996.

[6] L. Feng and G. Y. Wang, "Models for unifying rough set and vague set," Journal of Chongqing University of Posts and Telecommunications (Natural Science Edition), vol. 21, no. 4, pp. 449-454, 2009.

[7] T. Chaira and A. K. Ray, "A new measure using intuitionistic fuzzy set theory and its application to edge detection," Applied Soft Computing Journal, vol. 8, no. 2, pp. 919-927, 2008.

[8] T. Chaira, "Intuitionistic fuzzy segmentation of medical images," IEEE Transactions on Biomedical Engineering, vol. 57, no. 6, pp. 1430-1436, 2010.

[9] P. Kaur, A. K. Soni, and A. Gosain, "A robust kernelized intuitionistic fuzzy c-means clustering algorithm in segmentation of noisy medical images," Pattern Recognition Letters, vol. 34, no. 2, pp. 163-175, 2013.

[10] Z. Pei and L. Zheng, "A novel approach to multi-attribute decision making based on intuitionistic fuzzy sets," Expert Systems with Applications, vol. 39, no. 3, pp. 2560-2566, 2012.

[11] C.-L. Xu and L.-L. Wei, "Vague set method of multi-criteria fuzzy decision making," Systems Engineering-Theory \& Practice, vol. 30, no. 11, pp. 2019-2025, 2010 (Chinese).

[12] X. G. Zhou, C. Q. Tan, and Q. Zhang, Decision Theories \& Methods Based on Vague Set, Science Press, Beijing, China, 2009, (Chinese).

[13] H. W. Liu, "Vague set methods of multi-criteria fuzzy decision making," Systems Engineering-Theory \& Practice, vol. 24, no. 5, pp. 103-109, 2004 (Chinese).

[14] M.-H. Shu, C.-H. Cheng, and J.-R. Chang, "Using intuitionistic fuzzy sets for fault-tree analysis on printed circuit board assembly," Microelectronics Reliability, vol. 46, no. 12, pp. 21392148, 2006.

[15] L. Baccour and A. M. Alimi, "A comparison of some intuitionistic fuzzy similarity measures applied to handwritten Arabic sentences recognition," in Proceedings of the IEEE International Conference on Fuzzy Systems (FUZZ-IEEE '09), pp. 1389-1392, Jeju Island, Republic of Korea, August 2009.

[16] G. A. Papakostas, A. G. Hatzimichailidis, and V. G. Kaburlasos, "Distance and similarity measures between intuitionistic fuzzy sets: a comparative analysis from a pattern recognition point of view," Pattern Recognition Letters, vol. 34, no. 14, pp. 1609-1622, 2013.

[17] K. Atanassov, Intuitionistic Fuzzy Sets: Theory and Applications, Physica, Heidelberg, Germany, 1999.
[18] E. Szmidt and J. Kacprzyk, "Distances between intuitionistic fuzzy sets," Fuzzy Sets and Systems, vol. 114, no. 3, pp. 505-518, 2000.

[19] H.-W. Liu, "New similarity measures between intuitionistic fuzzy sets and between elements," Mathematical and Computer Modelling, vol. 42, no. 1-2, pp. 61-70, 2005.

[20] W.-L. Hung and M.-S. Yang, "Similarity measures of intuitionistic fuzzy sets based on Hausdorff distance," Pattern Recognition Letters, vol. 25, no. 14, pp. 1603-1611, 2004.

[21] P. Grzegorzewski, "Distances between intuitionistic fuzzy sets and/or interval-valued fuzzy sets based on the Hausdorff metric," Fuzzy Sets and Systems, vol. 148, no. 2, pp. 319-328, 2004.

[22] T.-Y. Chen, "A note on distances between intuitionistic fuzzy sets and/or interval-valued fuzzy sets based on the Hausdorff metric," Fuzzy Sets and Systems, vol. 158, no. 22, pp. 2523-2525, 2007.

[23] Y. Yang and F. Chiclana, "Consistency of 2D and 3D distances of intuitionistic fuzzy sets," Expert Systems with Applications, vol. 39, no. 10, pp. 8665-8670, 2012.

[24] A. G. Hatzimichailidis, G. A. Papakostas, and V. G. Kaburlasos, "A novel distance measure of intuitionistic fuzzy sets and its application to pattern recognition problems," International Journal of Intelligent Systems, vol. 27, no. 4, pp. 396-409, 2012.

[25] W. Wang and X. Xin, "Distance measure between intuitionistic fuzzy sets," Pattern Recognition Letters, vol. 26, no. 13, pp. 20632069, 2005.

[26] J. Kacprzyk, Multistage Fuzzy Control, Wiley, Chichester, UK, 1997.

[27] D. R. Luo and J. H. Xiao, "Distance and similarity between intuitionistc fuzzy sets," in Proceedings of the International Conference on Mechanical and Automation Engineering, pp. 157160, Jiujiang, China, 2013.

[28] Z. Liang and P. Shi, "Similarity measures on intuitionistic fuzzy sets," Pattern Recognition Letters, vol. 24, no. 15, pp. 2687-2693, 2003.

[29] C. L. Hwang and K. Yoon, Multiple Attribute Decision Making: Methods and Applications, A State of the Art Survey, Springer, Berlin, Germany, 1981.

[30] S.-M. Chen and J.-M. Tan, "Handling multicriteria fuzzy decision-making problems based on vague set theory," Fuzzy Sets and Systems, vol. 67, no. 2, pp. 163-172, 1994.

[31] D. H. Hong and C.-H. Choi, "Multicriteria fuzzy decisionmaking problems based on vague set theory," Fuzzy Sets and Systems, vol. 114, no. 1, pp. 103-113, 2000.

[32] F. Li, A. Lu, and L. Cai, "Multicriteria decision making based on Vague sets," Journal of Huazhong University of Science and Technology, vol. 29, no. 7, pp. 1-3, 2001.

[33] D.-F. Li, "Multiattribute decision making models and methods using intuitionistic fuzzy sets," Journal of Computer and System Sciences, vol. 70, no. 1, pp. 73-85, 2005. 


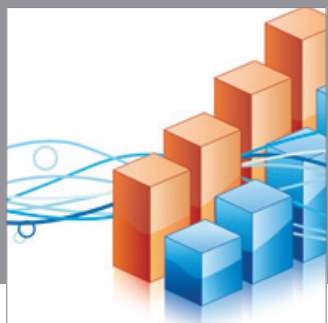

Advances in

Operations Research

mansans

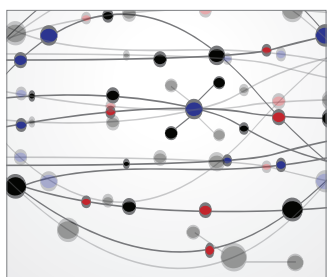

The Scientific World Journal
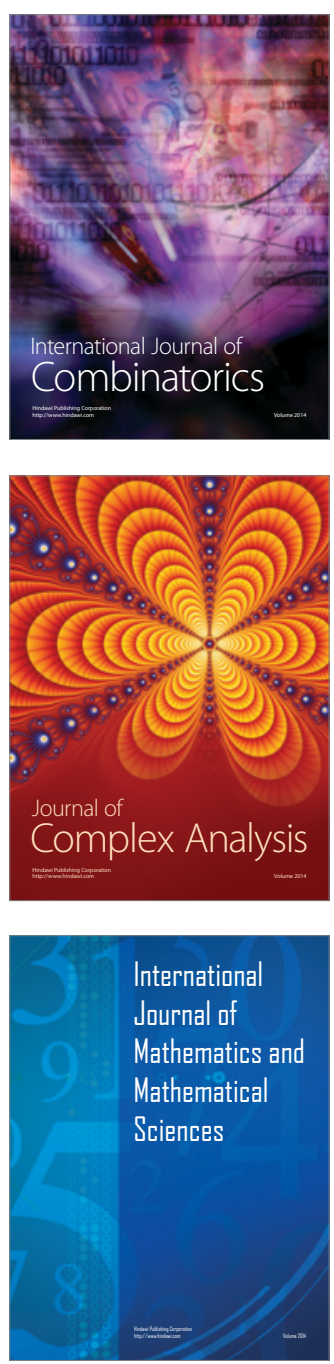
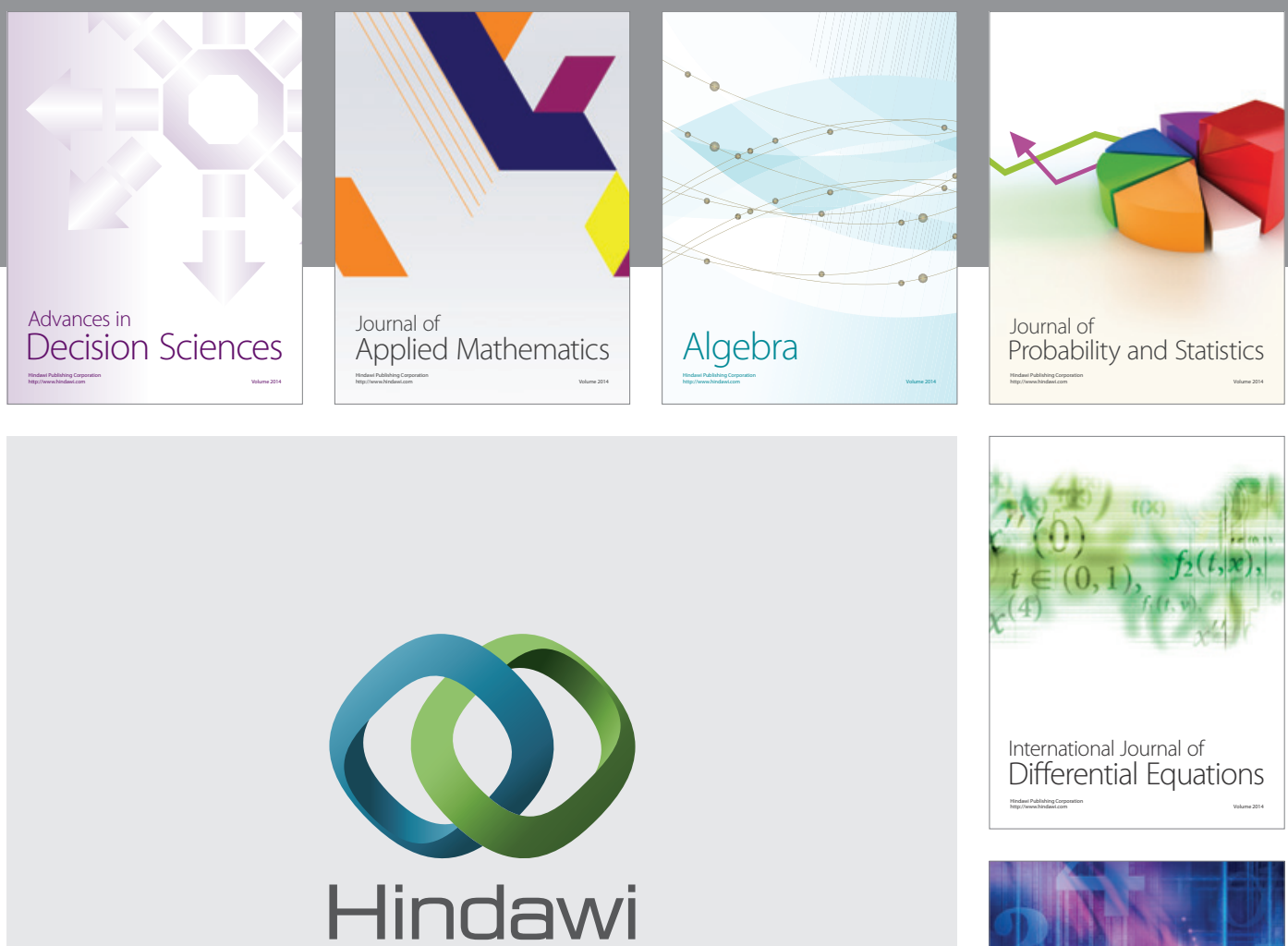

Submit your manuscripts at http://www.hindawi.com
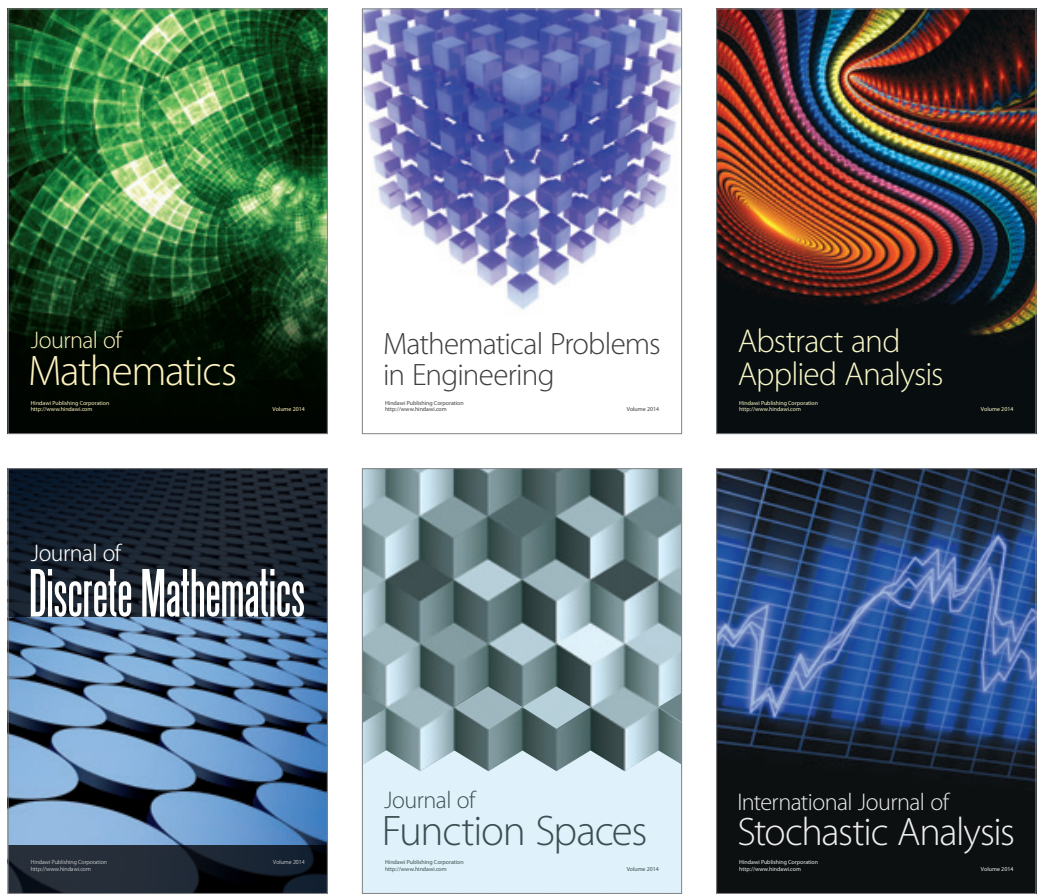

Journal of

Function Spaces

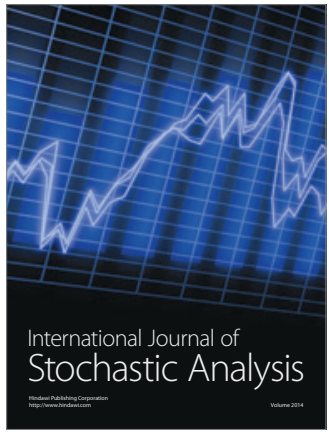

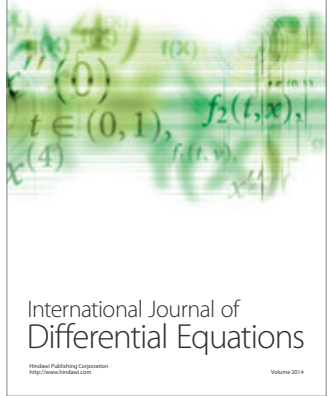
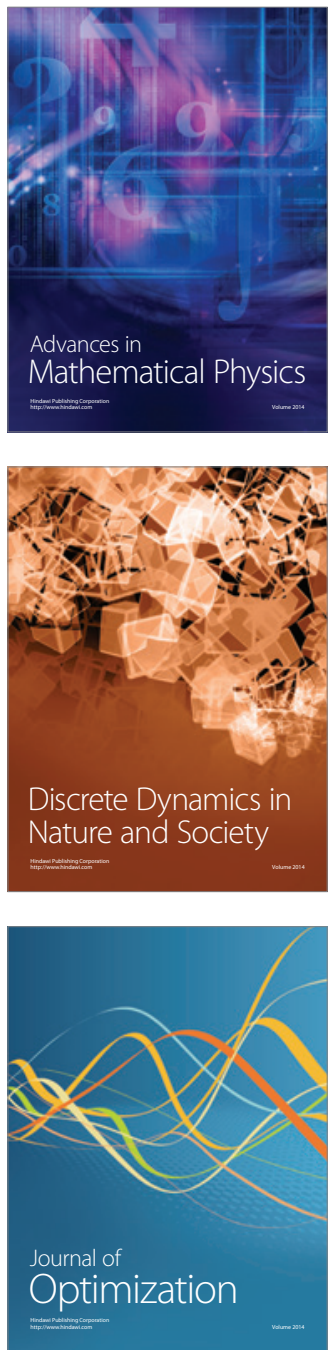